\title{
Nonfunctioning pituitary macroadenoma: a case report from the patient perspective
}

Craig A. Bauman ${ }^{1,2^{*}}$, James D. Milligan ${ }^{1,2}$, Tammy Labreche ${ }^{3}$ and John J. Riva ${ }^{1,4}$

\begin{abstract}
Background: Nonfunctioning pituitary macroadenoma (NFPA) is a tumour of the endocrine system that is virtually always benign and can be difficult to detect. This case report is presented from the patient's perspective to highlight experiences that led to the eventual diagnosis of this condition.

Case presentation: A 48 year-old male experienced prolonged and unexplained reduced athletic performance worsening over five years. The patient reported decreased libido, which initiated a testosterone blood test. This confirmed reduced testosterone levels and resulted in an endocrinology referral. A subsequent dynamic contrast MRI of the pituitary region revealed a mass. The most frequent symptoms of NFPA are visual field defects, headaches and features of hypopituitarism (includes fatigue, dizziness, dry skin, irregular periods in women and sexual dysfunction in men).
\end{abstract}

Conclusion: Clinicians should consider this differential diagnosis in middle-aged athletes with diminished athletic performance from an unknown cause, test visual fields and inquire if symptoms of headaches or hypopituitarism are present.

Keywords: Pituitary, Adenoma, Macroadenoma, Nonfunctioning, Middle-aged, Athletic, Performance

\section{Background}

Chiropractors are commonly utilized by middle-aged athletes to determine sources of reduced athletic performance [1]. Such clinicians are also often consulted for headache treatment [2]. For this reason chiropractors need to be aware of the potential diagnosis of nonfunctioning pituitary macroadenoma.

The pituitary is an endocrine (hormone-producing) gland that is located immediately below the base of the brain (Figs. 1 and 2) [3]. It approximates the size of a pea and is regulated by the hypothalamus [3]. It produces hormones that impact numerous parts of the body and stimulates all the other endocrine glands to produce their own hormones [3]. As a result of its complex tasks, it is frequently referred to as the 'master gland' [3].

Nonfunctioning pituitary macroadenoma (NFPA) is a nearly always benign tumour of the endocrine system $[3,4]$. NFPA is the most common adenoma in the pituitary gland,

\footnotetext{
* Correspondence: bauman@mcmaster.ca

${ }^{1}$ Department of Family Medicine, McMaster University, Hamilton, ON, Canada

${ }^{2}$ The Centre for Family Medicine Family Health Team, 25 Joseph Street,

Kitchener, ON, CanadaN2G 4X6

Full list of author information is available at the end of the article
}

accounting for $25-33 \%$ of these tumours $[5,6]$. At the time of diagnosis, most NFPAs are macroadenomas (greater than $1 \mathrm{~cm}$ in diameter) $[5,6]$. The prevalence of NFPA has been estimated at 22 cases per 100000 in cross-sectional studies [4]. They frequently present in those greater than 50 years of age [5], and the progression can vary widely, with some growing slowly and others becoming rapidly invasive [5].

The gold standard method of management of NFPA is surgical resection of the tumour via endoscopy using a transsphenoidal approach through the nasal cavity [4]. Prognosis for treated patients is generally very good [4]. Although NFPA is benign in nature, patients often need individualized management, lifelong diagnostic imaging and endocrinological monitoring [7]. This paper describes a specific case presentation around diminished athletic performance to highlight typical features related to NFPA from the patient perspective.

\section{Case Presentation \\ History}

I am a Canadian Doctor of Chiropractic and chiropractic clinician who is sharing their experience with NFPA. 


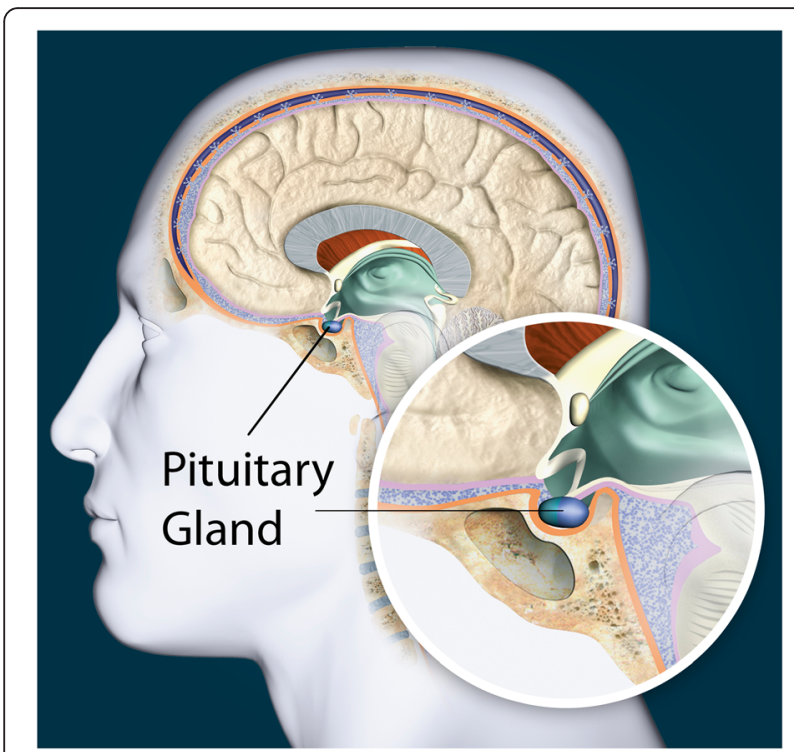

Fig. 1 Position of the Pituitary Gland in the Head. With permission from the Pituitary Society and licenced from Thinkstock by Getty Images

Fortunately, through fate or luck, circumstances led to successful management. My story starts as an age 43 male, five years prior to diagnosis. After an afternoon nap, I arose from bed quickly and had a brief intense pain sensed in the centre of my head. For 1 month afterwards, I had a mild sharp pain in the centre of my head for the first $200 \mathrm{~m}$ of a recreational run. I attended my family physician for this complaint and had a neurological examination, which was normal, and I was advised to come back if the pain returned. In hindsight, I felt this head pain was related to the NFPA; however this was not the typical type of headache presentation. Over the next 5 years I noticed a slow progressive reduction in strength that corresponded to a $30 \%$ decrease in my weight training ability. Also, I noticed a weight gain of 5-10 lb that was mostly abdominal which I initially thought was attributed to "getting older". When I ran a competitive 5- $\mathrm{km}$ race which resulted in me being $2 \mathrm{~min}$ and $12 \mathrm{~s}$ slower than the previous year despite increased training, this prompted me to return to my family physician.

Bloodwork was ordered. A mild anemia (normochromic normocytic) was detected, with hemoglobin of $117 \mathrm{~g} / \mathrm{L}$ (normal 135-175 g/L), hematocrit of $0.36 \mathrm{~L} / \mathrm{L}$ (normal $0.40-0.50 \mathrm{~L} / \mathrm{L}$ ), and red blood cell count of $3.83 \times$ E12/L (normal 4.50-6.00 x E12/L). Investigations to determine the etiology of the anemia included a chest $x$-ray, colonoscopy, gastroscopy and abdominal ultrasound, all of which were normal. During this time I reported to my family physician I was losing hair on my legs, my libido was very low along with having acquired cold sensitivity, hot flashes, anxiety and some noticeable hair growth on the scalp where I had been losing hair. By chance, during the period of when various diagnostic tests were occurring, I attended a family medicine continuing education conference where an endocrinologist spoke of the connection between low testosterone and a pituitary tumour. I later discussed this possibility with my family physician and a testosterone blood test was ordered.

\section{Physical examination}

The results of the testosterone tests showed testosterone was nearly absent at $0.5 \mathrm{nmol} / \mathrm{L}$ (normal $8.4-28.8 \mathrm{nmol} / \mathrm{L}$ ) and bioavailable testosterone was $0.1 \mathrm{nmol} / \mathrm{L}$ (normal is $3.6-11.2 \mathrm{nmol} / \mathrm{L}$ ). I was referred to an endocrinologist. A dynamic contrast MRI of the pituitary region (specifically the sella turcica) was ordered. A large $2.5 \mathrm{~cm}$ diameter mass was discovered in my pituitary region. A subsequent referral was made to a pituitary neurosurgical team and a series of tests and consults were booked (further bloodwork, neuro-opthalmology and endocrinology appointments). My bloodwork identified reduced pituitary hormone levels, which suggested the tumour was nonfunctioning. The luteinizing hormone $(\mathrm{LH})$ at $0.8 \mathrm{IU} / \mathrm{L}$ (normal male 1.7-8.6 IU/L) and follicle stimulating hormone (FSH) at $1.1 \mathrm{IU} / \mathrm{L}$ (normal male 1.5-12.4 IU/L) were also reduced. Diminished levels of these hormones were causing my testosterone to be low, which compromised hematopoiesis (i.e. the production of all types of blood cells) and resulted in the anemia [8]. Prolactin was elevated to $51 \mathrm{ug} / \mathrm{L}$ (normal male 4-15 ug/L) due to the tumour stalk effect (i.e. mass effect from the tumour on the pituitary infundibulum) $[7,9]$. Thyroid function was also compromised by the NFPA. My Free T4 was $11 \mathrm{pmol} / \mathrm{L}$ (normal 12-22 pmol/L) and Free T3 was $2.8 \mathrm{pmol} / \mathrm{L}$ (normal 3.1-6.8 pmol/L). I was prescribed testosterone gel and levothyroxine medication for replacement.

While frequently affected in NFPA, the neuroophthamologist concluded my visual fields were normal. A consult with an otolaryngologist (ENT) surgeon was required to evaluate the size of my nasal cavity in preparation for the surgical endoscopy procedure. In surgery, the endoscope is passed through the nasal cavity to make an opening in the sphenoid sinus, to access the pituitary region allowing the neurosurgeon to remove the tumour. This is called the transsphenoidal approach and its advantages are being less invasive and no visible scaring following neurosurgery [9].

\section{Imaging}

The neurosurgeon and the neuroradiologist reviewed my imaging (the previous dynamic contrast MRI and a recent $\mathrm{CT}$ ) and had a high degree of suspicion of a NFPA. Only after surgery and pathological sectioning of the tumour can a confirmatory diagnosis be made. 


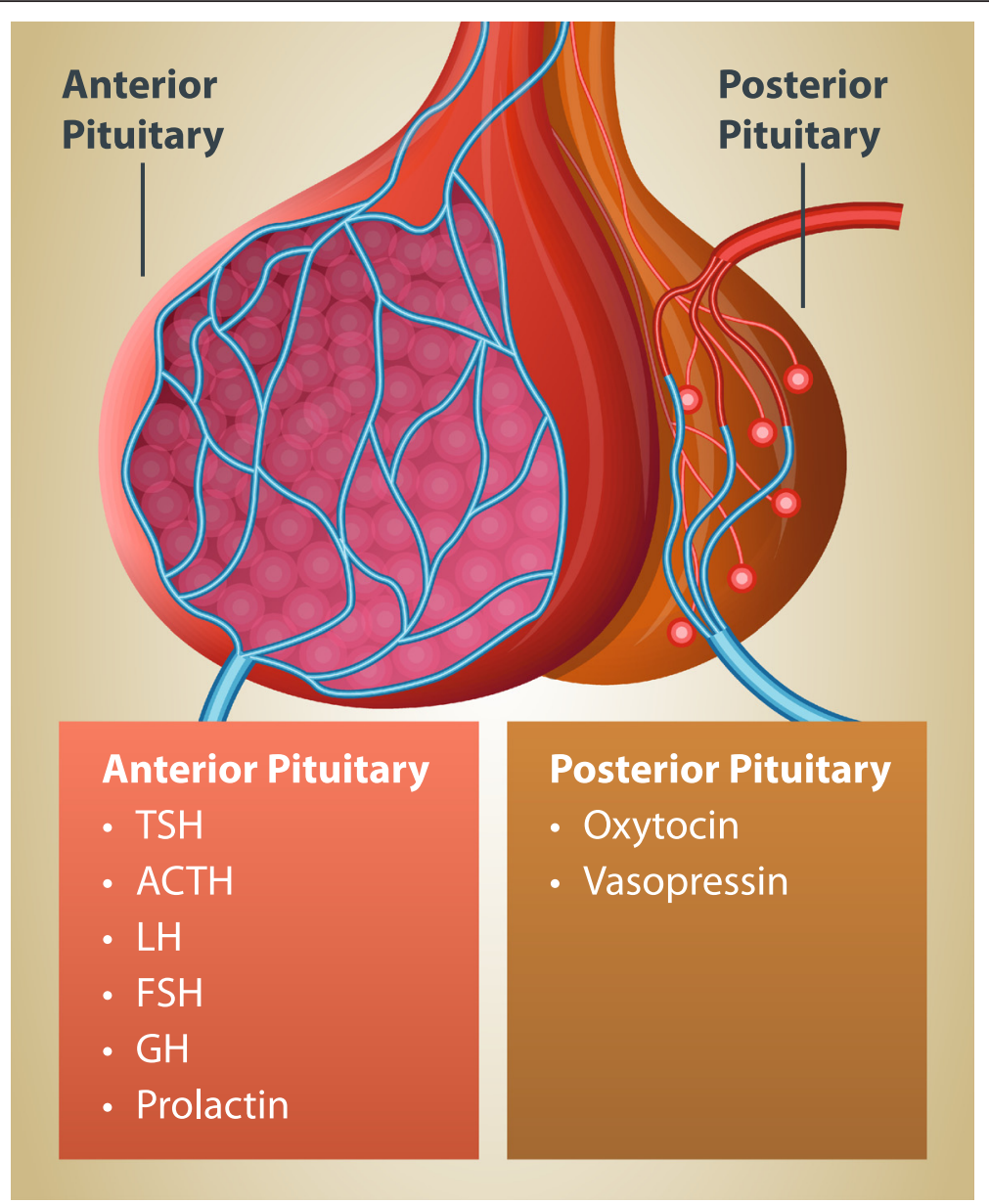

Fig. 2 Hormones of the Anterior and Posterior Pituitary Gland. TSH is thyroid stimulating hormone, ACTH is adrenocorticotropic hormone, LH is luteinizing hormone, FSH is follicle-stimulating hormone and GH is growth hormone. With permission from the Pituitary Society and licenced from Thinkstock by Getty Images

\section{Intervention}

Prior to surgery, I received meningococcal B immunizations as ENT surgery has an eleven-fold and neurosurgery has a seven-fold, increased risk of meningitis in the first 10 days following surgery [10]. With a MRI just before surgery, adhesive stickers known as fiducial markers were attached to my head. This assists the neuro-navigation of the neurosurgeon to help orient themselves relative to the tumour position in my head during the surgery. In the operating room, my head was placed in a form-fitting cradle for stabilization. Later, when under anesthetic, a series of pins were screwed into my skull to further stabilize it, as the surgeon has to be very precise during the procedure. The entire surgical procedure typically takes up to $5 \mathrm{~h}$.

\section{Conclusions}

The surgery was completed without incident and I was returned to the recovery room after approximately $4 \mathrm{~h}$. I had a subsequent follow up with my care team one month after surgery, where the pathological sectioning confirmed a NFPA. This was a tremendous relief as other, more sinister tumours were a possibility. Radiation therapy was considered but not deemed required. Future ongoing screening recommendations for recurrence includes annual MRI monitoring.

\section{Discussion}

\section{Clinical presentation}

Clinically, NFPA comprise about $80 \%$ of all pituitary macroadenomas [5]. It is likely there are many in the population with undetected macroadenomas [11]. Imaging of the head is now commonly implemented as part of the workup of many unrelated medical cases [5] and as a result, pituitary lesions are often detected incidentally [5]. Nonfunctioning categorizes the tumour cells as not secreting hormones versus functioning adenomas. This can be advantageous; but also can make discovery difficult as there is absence of a readily identifiable syndrome of pituitary hormone hypersecretion often leading to growth of these tumours for many years before discovery [9]. Many cases presenting with NFPA have at 
least some pituitary insufficiency [7]. The majority of patients who have NFPA will seek medical attention because of a mass effect (i.e. the growing tumour applying pressure to tissues) from the macroadenoma [9]. The main complaints or symptoms associated with mass effect are visual field defects with or without decreased visual acuity, unspecified headache and effects of hypopituitarism (Table 1) [3]. As a result, many macroadenomas are often uncovered at the optometrist [9].

Visual field defects exist in $60-70 \%$ of patients with NFPA at the time of suspicion of the diagnosis, which results from pressure on the optic chiasm by the tumour $[7,9]$. Patients are usually unaware of the deficiency, which only becomes apparent during formal visual field testing [9]. Compression of the chiasm can result in a symmetrical bi-temporal hemianopia (i.e. loss of the outer field of vision in both eyes), but more commonly there is an asymmetrical bi-temporal hemianopia or even a unilateral temporal field defect $[5,7]$. The chiropractic clinician could test visual fields if NFPA is suspected using the confrontation visual field test. Headache, often localized to the brow or periorbital region, is present in $40-60 \%$ of all patients and is generated by increased intracranial pressure and/or stretching of the dura mater [7, 12]. The neurosurgeon stated that NFPA, along with some other pituitary tumours, are increasingly detected in middle-aged athletes with reduced athletic performance and signs of hypopituitarism. Inquiry as to the presence of these symptoms should be made in the patient history. As chiropractors are consulted by mature athletes, NFPA should remain in their differential diagnosis when such signs are present and a referral made to their physician with a note.

Differential diagnoses of NFPA includes craniopharyngiomas, germinomas, metastatic tumours and vascular aneurysms [13]. Differential diagnoses for NFPA visual field defects includes compressive lesions (eg, craniopharyngiomas), ischemic lesions (eg, pituitary apoplexy), inflammatory lesions (eg, multiple sclerosis), and toxic lesions (eg, pheniprazine) [12]. Differential diagnoses of NFPA headaches includes cluster headaches, migraine variants and trigeminal neuralgia [14]. Fatigue could be caused by infection, anemia, endocrinopathies (eg, diabetes and hypothyroidism), sleep disturbances (eg, sleep apnea), medication side-effects, adrenal insufficiency (usually other symptoms and signs) and malignancies (rare) [15]. Overtraining syndrome in athletes can also lead to fatigue [16].

Pituitary tumours can be classified by size or by function [5]. The best current diagnostic imaging method for evaluating pituitary adenomas is MRI [7]. Size, as determined by MRI, less than $1 \mathrm{~cm}$ in diameter is considered a microadenoma and those tumours greater than $1 \mathrm{~cm}$ in diameter are considered a macroadenoma $[5,11]$. Function is described by the detectable increase of a pituitary hormone through blood tests [5]. Therefore, if no hormones were manufactured, the tumour is defined nonfunctioning. These tumours may also be classified according to immunohistochemistry [11].

NFPAs that touch the optic apparatus, without visual dysfunction, may be followed with close ophthalmological and radiographic monitoring, pending tumour and imaging characteristics [17]. Surgery should be contemplated for those patients with concerning tumour growth, loss of endocrinological function, a lesion close to the optic chiasm, a desire to become pregnant, or unremitting unspecified headaches [18].

\section{Treatment}

The majority of patients with a large NFPA should have pituitary surgery $[5,6,9]$. Surgical morbidity and cure rate have been found to be highly reliant on the skill of the pituitary surgeon $[7,9,19]$. The favoured surgery is a transsphenoidal approach, due to less associated morbidity and mortality [9]. The surgical management of

Table 1 Symptoms and Signs of Pituitary Hormone Deficiency. With permission from the Pituitary Society

\begin{tabular}{|c|c|c|}
\hline Pituitary Hormone & Target Organs & Effect of Deficiency \\
\hline$\overline{\mathrm{ACTH}}$ & Adrenal glands: cortisol and DHEA & Fatigue, low sodium in blood, weight loss, skin pallor \\
\hline $\mathrm{TSH}$ & Thyroid gland: thyroid hormone & Fatigue, weight gain, dry skin, sensitivity to cold, constipation \\
\hline LH and FSH in Women & $\begin{array}{l}\text { Ovaries: estrogen, progesterone; } \\
\text { ovulation }\end{array}$ & Loss of periods, loss of sex drive, infertility \\
\hline $\mathrm{LH}$ and $\mathrm{FSH}$ in Men & $\begin{array}{l}\text { Testes: testosterone, sperm } \\
\text { production }\end{array}$ & Loss of sex drive, erectile dysfunction, impotence, infertility \\
\hline GH in Children \& Adolescents & Bone, muscle, fat & $\begin{array}{l}\text { Lack of growth (height); increased body fat, failure to achieve normal peak } \\
\text { bone mass }\end{array}$ \\
\hline $\mathrm{GH}$ in Adults & Whole body & Poor quality of life, increased body fat, decreased muscle and bone mass \\
\hline$P R L$ & Breast & Inability to breast feed \\
\hline Oxytocin & Breast, Uterus & Complete deficiency could make breast feeding difficult \\
\hline $\begin{array}{l}\text { Antidiuretic hormone } \\
\text { (vasopressin) }\end{array}$ & Kidney & Frequent urination (day \& night), dilute urine, excessive thirst \\
\hline
\end{tabular}


macroadenomas (greater than $1 \mathrm{~cm}$ ) is precipitated by the greater probability that these tumours will increase in size over time leading to resultant mass effects. The initial goals of post surgical therapy are to mitigate any future mass effect and to return normal endocrine function [9].

Because there is a known correlation between the severity of visual loss before surgery and persisting visual field defects after treatment, the wait time for surgery is typically expedited [7]. Besides the improvement of visual function, full cessation of headaches is likely to occur after surgery for NFPA [7]. During post surgical followup, careful assessment and replacement of pituitary deficiencies is implemented [7]. It is possible that future advancements in the field of neurosurgery, such as endoscopic techniques utilizing combination with neuronavigation, will further improve surgical outcomes and improve the long-term prognosis [7].

NFPA treatment can involve single or combinations of surgical intervention, radiotherapy or pharmacological treatment [5]. It is essential that all options for therapy are discussed and inclusion of surgical, endocrine and oncology providers is often provided in a multidisciplinary team setting [5]. For those adenomas less than $1 \mathrm{~cm}$ in diameter and restricted to the sella, a strategy of watchful waiting and serial MRI scans is often employed [5]. It is necessary to have ruled out any secondary hormonal deficiencies to optimize quality of life [5].

Assuming hormonal normality, then close monitoring may be all that is needed [5]. With no hormone irregularity present, follow up in this instance relies upon serial screening [5]. For those adenomas larger than $1 \mathrm{~cm}$ (the majority), after excluding hormone deficiencies, it is common to proceed to surgical management [5]. These macroadenomas more commonly exert pressure effects [5].

Pharmacological treatment of the NFPA tumour itself is typically unsuccessful $[5,9]$. Medical management is frequently based around regular follow-up, monitoring of visual problems and secondary hormone deficiencies [5]. Periodically, tissue regrowth develops post surgically and, although a repeat surgical intervention can be pursued, adjunctive radiotherapy also remains a useful option [5]. Indeed, radiation therapy may be proposed if the patient is not suited for surgery or if complete tumour removal is not achievable [5, 20, 21]. Radiosurgery for NFPAs is quite effective, with usually around a $90 \%$ success rate for tumour control [20, 21].

The greatest risk of transsphenoidal neurosurgery is a postoperative cerebrospinal fluid leak [4]. When this occurs, a clear fluid drips out of the nose quite steadily when leaning forward. Symptoms of a leak may also include a headache, however headache can also be expected after the neurosurgical procedure itself.
Post-surgery, rest and avoidance of straining activities (valsalva) is required with an anticipated return to work in approximately 2 months.

All patients that require hydrocortisone replacement should carry a steroid card (e.g. instructions in case of an emergency) and participate in education about sick day rules (sickness stress requires increased cortisol which can no longer be produced) [5]. These sick day rules will be advised by a physician and frequently involves doubling the usual hydrocortisone dose for 1 to 3 days [22]. An adrenal crisis (acute cortisol insufficiency) can ensue during times of illness which can be life threatening and must be managed promptly [23]. Symptoms include unusual tiredness and weakness, dizziness when standing up, nausea, vomiting, diarrhea, loss of appetite, stomach ache and joint aches and pains [22].

\section{Prognosis and adverse events}

In NFPA, no single conclusive predictive factor has been identified that is associated with recurrence [24]. NFPAs, with or without perceptible residual tumour, need stratification of treatment and radiological/endocrinological follow-up strategies [6]. The tumour growth-free survival rates at 5 years are $85 \%$ with intrasellar remnant and $49 \%$ with extrasellar remnant and at 10 years are $58 \%$ with intrasellar remnant and $23 \%$ with extrasellar remnant [6]. Fortunately, $54 \%$ of residual tumours will not regrow again after surgery $[6,9]$. Therefore, it is advised that MRI should be repeated annually in these patients [6]. Reoperation or radiotherapy should be contemplated only when the tumoural regrowth is confirmed, except where the adenomatous residue is voluminous and close to the optic nerves/chiasm [6]. Whether NFPAs are associated with an increased mortality or reduced lifespan is still unknown [8].

Adverse events from a transsphenoidal approach were linked with $1 \%$ mortality and $5 \%$ important complications (e.g. cerebrospinal fluid leakage, fistula, meningitis, persistent diabetes insipidus or new visual field defect) [4]. Olfaction may be impacted by this surgical technique $[25,26]$. Of patients with visual field defects prior to surgery, $78 \%$ had recovery in their visual field defects [4]. Conversely, gains in pituitary function occurred in less than a third of the patients [4]. Complete removal of the lesions, as evaluated by the operating surgeons, occurs in approximately $20 \%$ of the cases [4].

\section{Limitations}

A key limitation of this paper may be the inherent/unintentional bias that the principal author may bring to the report since it's from the patient-perspective. This case report may have biased observations in how the principal author recounted the details. 


\section{Case conclusion}

One month after surgery, I was able to stop taking hydrocortisone as my pituitary returned to producing sufficient hormone. I was off work a total of 6 weeks. Six months post surgery, I felt I was in excellent health, had returned to running and strength training and my body weight had returned to the level it was 5 years prior. The 6 month follow up dynamic contrast MRI showed no definite tumour residual. Ongoing yearly MRIs will occur to monitor for regrowth. I will continue on testosterone and levothyroxine medication indefinitely and levels monitored. Truly, I am delighted with the outcome and decided to share the learning experience through a case report for other clinicians as a patient may describe these slowly progressive symptoms during a consultation.

\section{Take home points}

- Nonfunctioning pituitary macroadenoma can be difficult to detect

- Vision changes, headaches and symptoms of hormone irregularity offer clues to the tumour's presence

- Unexplained reduced performance in middle-aged athletes may be an indicator

- Post-surgery, yearly imaging may be required to monitor for tumour recurrence

- Life-long hormone replacement therapy may be required

\section{Consent}

Written informed consent was obtained from the patient for publication of this case report. A copy of the written consent is available for review by the Editor-in-Chief of this journal.

\section{Competing interests}

The authors declare that they have no competing interests.

\section{Authors' contributions}

CB contributed to the literature review. CB, JM and JR contributed to the writing of the manuscript. All authors read and approved the final manuscript.

\section{Authors' information}

CB and JR are members of the McMaster Chiropractic Working Group, which receives in kind support from the Canadian Chiropractic Association.

\section{Acknowledgements}

The patient in this case review is the principal author. This paper is dedicated to Mr. Thomas Hunter, partner at Gowlings Law Firm Waterloo Region Office. John Riva is supported by a PhD training award from the NCMIC foundation. A special thank you to Dr. Neil Duggal and the entire pituitary neurosurgical team at London Health Sciences, London, Ontario, Canada.

\section{Author details}

${ }^{1}$ Department of Family Medicine, McMaster University, Hamilton, ON, Canada. ${ }^{2}$ The Centre for Family Medicine Family Health Team, 25 Joseph Street, Kitchener, ON, CanadaN2G 4X6. ${ }^{3}$ School of Optometry and Vision Science, University of Waterloo, Waterloo, ON, Canada. ${ }^{4}$ Department of Clinical Epidemiology \& Biostatistics, McMaster University, Hamilton, ON, Canada.
Received: 9 November 2015 Accepted: 2 March 2016

Published online: 11 April 2016

\section{References}

1. Miners AL. Chiropractic treatment and the enhancement of sport performance: a narrative literature review. J Can Chiropr Assoc. 2010;54(4):210-21.

2. D'Sylva J, Miller J, Gross A, Burnie SJ, Goldsmith CH, Graham N, Haines T, Brønfort G, Hoving JL. Manual therapy with or without physical medicine modalities for neck pain: a systematic review. Man Ther. 2010;15(5):415-33.

3. The pituitary society. Viewed April 27, 2015. http://www.pituitarysociety.org.

4. Murad MH, Fernández-Balsells MM, Barwise A, Gallegos-Orozco JF, Paul A, Lane MA, et al. Outcomes of surgical treatment for nonfunctioning pituitary adenomas: a systematic review and meta-analysis. Clin Endicrinol (Oxf). 2010;73:777-91.

5. Saunders S, Vora JP. Endocrine evaluation of pituitary tumours. Br J Neurosurg. 2008;22(4):602-8.

6. Chen Y, Wang CD, Su ZP, Chen YX, Cai L, Zhuge QC, Wu ZB. Natural history of postoperative nonfunctioning pituitary adenomas: a systematic review and meta-analysis. Neuroendocrinology. 2012;96:333-42.

7. Dekkers OM, Pereira AM, Romijn JA. Treatment and follow-up of clinically nonfunctioning pituitary macroadenomas. J Clin Endocrinol Metab. 2008;93(10):3717-26.

8. Ellegala DB, Alden TD, Couture DE, Vance ML, Maartens NF, Laws Jr ER. Anemia, testosterone, and pituitary adenoma in men. J Neurosurg. 2003:98(5):974-7.

9. Jaffe CA. Clinically non-functioning pituitary adenoma. Pituitary. 2006;9:317-21.

10. Howitz MF, Homøe P. The risk of acquiring bacterial meningitis following surgery in Denmark, 1996-2009: a nationwide retrospective cohort study with emphasis on ear, nose and throat (ENT) and neurosurgery. Epidemiol Infect. 2014;142:1300-9.

11. Ezzat S, Asa SL, Couldwell WT, Barr CE, Dodge WE, Vance ML, et al. The prevalence of pituitary adenomas: a systematic review. Cancer. 2004;101(3):613-9.

12. Lee AG, Lai KE, Jirawuthiworavong GV. Pituitary adenoma. Eyewiki. Viewed January 24, 2016. http://eyewiki.aao.org/Pituitary_Adenoma.

13. Mulinda JR: Pituitary macroadenomas differential diagnosis. Medscape. Viewed January 24, 2016. http://emedicine.medscape.com/article/123223differential

14. Blanda M: Cluster Headache Differential Diagnoses. Medscape. Viewed January 24, 2016. http://emedicine.medscape.com/article/1142459-differential

15. Ponka D, Kirlew M. Top 10 differential diagnoses in family medicine: fatigue. Can Fam Physician. 2007;53(5):892.

16. Budgett R. Fatigue and underperformance in athletes: the overtraining syndrome. Br J Sports Med. 1998;32(2):107-10.

17. Ryu WH, Tam S, Rotenberg B, Labib MA, Lee D, Nicolle DA, et al. Conservative management of pituitary macroadenoma contacting the optic apparatus. Can J Neurol Sci. 2010;37:837-42.

18. Freda PU, Beckers AM, Katznelson L, Molitch ME, Montori VM, Post KD, et al. Pituitary Incidentaloma: An Endocrine Society Clinical Practice Guideline. J Clin Endocrinol Metab. 2011;96(4):894-904.

19. Leach P, Abou-Zeid AH, Kearney T, Davis J, Trainer PJ, Gnanalingham KK Endoscopic transsphenoidal pituitary surgery: evidence of an operative learning curve. Neurosurgery. 2010;67(5):1205-12.

20. Ding D, Starke RM, Sheehan J. Treatment paradigms for pituitary adenomas: defining the roles of radiosurgery and radiation therapy. J Neurooncol. 2014;117:445-57.

21. Brada M, Jankowska P. Radiotherapy for Pituitary Adenomas. Endocrinol Metab Clin N Am. 2008;37:263-75.

22. National institutes of health clinical center. Managing adrenal insufficiency. Viewed April 26, 2015. http://www.cc.nih.gov/ccc/patient_education/pepubs/ mngadrins.pdf.

23. Corenblum B, Mulinda JR, Romesh K: Hypopituitarism (panhypopituitarism). Medscape. Viewed October 30, 2015. http://emedicine.medscape.com/article/ 122287-overview.

24. Roelfsema F, Biermasz NR, Pereira AM. Clinical factors involved in the recurrence of pituitary adenomas after surgical remission: a structured review and metaanalysis. Pituitary. 2012;15:71-83.

25. Rotenberg BW, Saunders S, Duggal N. Olfactory outcomes after endoscopic transsphenoidal pituitary surgery. Laryngoscope. 2011;121(8):1611-3.

26. Tam S, Duggal N, Rotenberg BW. Olfactory outcomes following endoscopic pituitary surgery with or without septal flap reconstruction: a randomized controlled trial. Int Forum Allergy Rhinol. 2013;3(1):62-5. 